\title{
Şekil Hatırlamalı Ni-45.16\%Ti Alaşımının Hava Atmosferinde Sıcaklığın Oksidasyon Davranışına Etkisi
}

\author{
Ercan ERCAN ${ }^{*}$, Fethi DAĞDELEN ${ }^{2}$ \\ ${ }^{1}$ Bitlis Eren Üniversitesi, Fen-Edebiyat Fakültesi, Fizik Bölümü, Bitlis \\ ${ }^{2}$ Firat Üniversitesi, Fen Fakültesi, Fizik Bölümü, Elazı̆̆
}

\begin{abstract}
Özet
NiTi alaşımının oksidasyon davranışı, thermogravimetrik analiz (TGA), diferansiyel taramalı kalorimetresi (DSC), $\mathrm{X}$-1şını difraksiyonu (XRD) ve taramalı elektron mikroskobu enerji dağılımlı X-1şını spektrometresi (SEM-EDX) analizleri ile izotermal sıcaklıklarda araştırıldı. Ni-45.16\% Ti (atomikçe) alaşımı $400-800{ }^{\circ} \mathrm{C}$ sıcaklıkları arasında 1 saat süresince hava atmosferine maruz bırakıldı. Hava atmosferindeki nikelce zengin NiTi alaşımı, $400^{\circ} \mathrm{C}$ üzerindeki sıcaklıklarda farklı oksidasyon davranışı sergilediği görüldü. NiTi alaşımı için oksidasyon davranışının aktivasyon enerjisi (Arrhenius eğrisi kullanılarak) 111,64 kj/mol olarak hesaplandı. DSC ölçümlerine göre, alaşımın dönüşüm sıcaklıklarının $\left(\mathrm{M}_{\mathrm{s}}, \mathrm{M}_{\mathrm{f}}, \mathrm{A}_{\mathrm{s}}\right.$ and $\left.\mathrm{A}_{\mathrm{f}}\right)$ arttığı ve $500^{\circ} \mathrm{C}$ üzerindeki sicaklıklarda $\mathrm{R}$ fazının kaybolduğu görüldü. Issl işlem görmüş numunelerin $\mathrm{X}$-1şını difraksiyon desenleri ile özellikle $\mathrm{TiO}_{2}$ oksit piklerinin olduğu görüldü. İzotermal sıcaklık ile $\mathrm{TiO}_{2}$ ve $\mathrm{Ni}_{3} \mathrm{Ti}$ piklerinin miktarlarının arttığını, böylece NiTi (B2), NiTi (B19) ve $\mathrm{Ni}_{4} \mathrm{Ti}_{3}$ piklerinin azaldığı X-ışını analizleri ile gözlendi. Ayrıca asıl oksitlerin SEM-EDX ölçümleri ile belirlenip $\mathrm{TiO}$ ve $\mathrm{TiO}_{2}$ olduğu gözlendi.
\end{abstract}

Anahtar Kelimeler: Oksidasyon davranışı, aktivasyon enerjisi, hava atmosferi

\section{Influence of Temperature on Oxidation Behavior of Ni-45.16\% Ti Shape Memory Alloy in Air Atmosfer}

\begin{abstract}
Oxidation behavior of NiTi alloy has been investigated under isothermal temperature by thermo gravimetric analysis (TGA), differential scanning calorimeter (DSC), X-ray diffraction (XRD) and scanning electron microscopy equipped with a dispersive X-ray (SEM-EDX) spectroscope systems. The Ni-45.16\% Ti (composition in atomic percent) was exposed to air atmosphere, i.e., between $400^{\circ} \mathrm{C}$ and $800^{\circ} \mathrm{C}$, for $1 \mathrm{~h}$. It was found that Ni-rich NiTi alloy exhibits different oxidation behaviour at temperatures above $400^{\circ} \mathrm{C}$ in air atmosphere. The activation energy (estimated from Arrhenius plots) of oxidation reaction for NiTi alloy was determined to be 111,64 kj/mol. According to DSC measurements, the transformation temperature of alloy $\left(\mathrm{M}_{\mathrm{s}}, \mathrm{M}_{\mathrm{f}}, \mathrm{A}_{\mathrm{s}}\right.$ and $\left.\mathrm{A}_{\mathrm{f}}\right)$ was increased and also R phase disappeared above $500^{\circ} \mathrm{C}$. X-ray diffraction patterns of the heat-treated specimens contain oxide peaks, mainly belonging to $\mathrm{TiO}_{2}$. X-ray analyses demonstrate that the amount of the $\mathrm{TiO}_{2}$ and $\mathrm{Ni}_{3} \mathrm{Ti}$ peaks expands with isothermal temperature while that of $\mathrm{NiTi}(\mathrm{B} 2), \mathrm{NiTi}(\mathrm{B} 19)$ and $\mathrm{Ni}_{4} \mathrm{Ti}_{3}$ peaks decreases. In addition to the formal oxides were determined by means of SEM-EDX measurements and obtain oxides are $\mathrm{TiO}$ and $\mathrm{TiO}_{2}$.
\end{abstract}

Keywords: Oxidation behavior, activation energy, air atmosphere

\section{Giriş}

Son yıllarda şekil hatırlamalı alaşımların, fonksiyonel akıllı materyallerde kullanılması önemli derecede dikkat çekmektedir [1]. Ancak şekil hatırlamalı alaşımların uzun süreli hava atmosferine maruz kalması,

\footnotetext{
*Sorumlu Yazar:eercan@beu.edu.tr
} 
oksitlenmesine neden olmaktadır. Oksitlenen şekil hatırlamalı alaşımın mikro yapısında martensit fazın kararsızlaşması ve bundan dolayı şekil hatırlama özelliğinde azalmaların oluştuğu gözlenmiştir [2].

Şekil hatırlamalı alaşımlar arasında NiTi alaşımı, iyi bir biyouyumluluğa, ısıtılınca şekil değiştirme yeteneğine ve eşsiz mekaniksel özelliklere sahip olmasından dolayı medikal uygulamalarda sıkça tercih edilen bir alaşımdır [3,4]. Ayrıca bu alaşımlar iyi bir korozyon direncine sahip oldukları için kateter, stent, vena cana inferior filtresi ve ortodontik tellerde kullanılmaktadır [5,6]. Günümüzde NiTi şekil hatırlamalı alaşımların başta uzay ve uçak mühendisliği alanlarında olmak üzere, savunma sanayinin birçok alanında ve tıp uygulamalarında kullanımı diğer sistemlere göre tercih edilir hale gelmiştir.

NiTi alaşımları oda sıcaklığında pasif oksit tabakalarına sahiptir. Ancak bu alaşımların yüksek sıcaklıktaki yüzey oksidasyon davranışları alaşımın kompozisyonuna ve yüzey uygulamalarına bağlı olarak aktif hale geçer [7]. NiTi şekil hatırlamalı alaşımlarda oksit oluşumunu anlamak için birçok çalışma yapılmıştır [8-10]. Ancak yine de NiTi alaşımının oksidasyon davranışının üzerine eksiklikler olduğu düşünülmektedir.

\section{Metaryal ve Metot}

$\mathrm{Bu}$ çalışmada, Nimesis technology (Fransa) firması tarafindan $2 \mathrm{~mm}$ çapında tel şeklinde üretilen Ni45.16\% Ti (atomikçe) şekil hatırlamalı alaşımının oksidasyon davranışı hava atmosferinde yüksek sıcaklıklar için detaylı olarak incelenmiştir. NiTi alaşımının yüksek sıcaklıkta oksitlenmesinden doğan değişimlerin, alaşımın dönüşüm sıcaklığına, mikro yapı ve kristal yapıya etkisi TG/DTA, DSC, SEMEDX ve XRD ile incelenmiştir.

Şekil hatırlamalı NiTi alaşımının izotermal oksidasyon davranışını belirlemek için Perkin Elmer Pyris Thermogravimetrik (TG/DTA) cihazı yardımıyla incelendi. Şekil 1'de görüldügü gibi alaşımın oksidasyon davranışını belirlemek için $20^{\circ} \mathrm{C} /$ dak. 1 sıtma hızı ile oda sıcaklığından $900^{\circ} \mathrm{C}$ ' ye kadar 1sıtıldı. Numunede $30^{\circ} \mathrm{C}$ ile $400^{\circ} \mathrm{C}$ aralığında sergilenen oksitlenme davranışının doğrusal bir değişim olduğu ve bu aralıkta numunenin kütle kazanımının ise yaklaşık (gram başına) \% 0, 05/g kadar olduğu görüldü. $400^{\circ} \mathrm{C}$ ile $900^{\circ} \mathrm{C}$ sıcaklıkları aralığında sergilenen oksitlenme davranışının ise parabolik olarak arttığı ve bu sıcaklıklar aralığında ise numunenin kütle kazanımının (gram başına) \% 0, 32/g olduğu belirlendi. Bu sonuçlara göre, kütle kazanımının fazla olduğu $400-900^{\circ} \mathrm{C}$ aralığında ki 400, 500, 600, 700 ve $800^{\circ} \mathrm{C}$ olarak beş farklı termal oksidasyon sıcaklıkları seçildi.

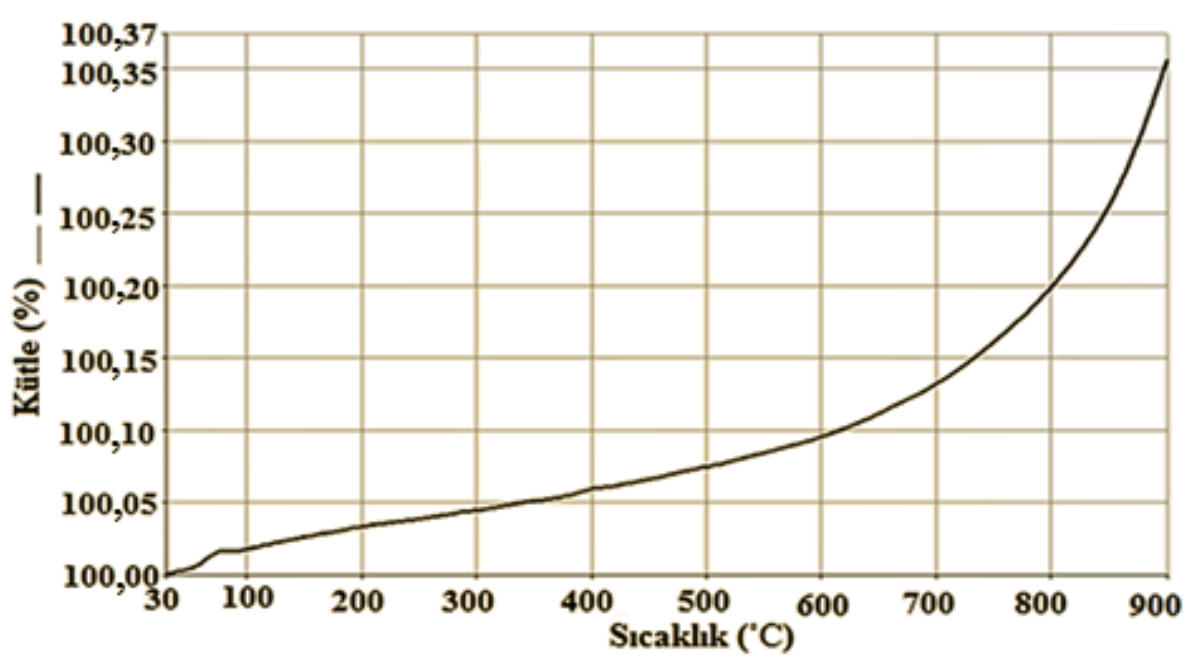

Şekil 1. $30-900^{\circ} \mathrm{C}$ aralığında nonizotermal TG ölçümü 
Numunelerimizin oksitlenme davranışları belirlenirken aşağıdaki yöntem uygulandı. Termal oksidasyon sıcaklıkları için belirlenen beş farklı sıcaklık için numuneler hazırlandı. Her sıcaklık için hazırlanan numuneler oda sıcaklığından bu sıcaklıklara ulaşıncaya kadar $50^{\circ} \mathrm{C} / \mathrm{dak}$ ssıtma hızı ile ayrı ayrı 1sıtıldı. Isıtma esnasında numunelerin oksitlenmesini engellemek için $100 \mathrm{ml} /$ dak azot gazı verildi. Daha sonra oksitlenmesini istediğimiz sıcaklıklara gelindiğinde azot gazı kesilerek hava ortamında 1 saat süreyle oksitlenmeye bırakıldı.

Belirlenen sıcaklıklardaki alaşımların dönüşüm sıcaklıklarını belirtmek için Perkin Elmer Sapphire cihazı ile $20^{\circ} \mathrm{C} /$ dak ssıtma hızı ve numunelerin tekrardan oksitlenmesini engellemek için 100 $\mathrm{ml} /$ dak azot gazı verilerek DSC ölçümleri alındı.

Oksitlenmeye maruz bırakılan alaşımların yüzey mikrografları JEOL JSM-7001F marka SEM cihazı ile incelendi.

Bruker D8 Discover Da vinci Design bilgisayar kontrollü X-1şını difraktometresi ile $(\mathrm{CuK} \alpha$ $\lambda=1,5418$ radyasyonu kullanılarak) numunelerin $X-1 s ̧ ı n ı$ analizleri $30-80^{\circ}$ arasında $4 \%$ dak sabit tarama hızı ile yapıldı.

\section{Bulgular ve Tartışma}

TGA analizi yapılan numunelerden elde edilen miligram başına oksitlenme davranışının zamana göre değişimi Şekil 2'de verildi. Buna göre kütle başına düşen oksitlenme miktarlarına bakıldığında; $400^{\circ} \mathrm{C}$ ile $500^{\circ} \mathrm{C}$ sıcaklıklarında oksitlenmeye maruz bırakılan numunelerin kütle kazançları hemen hemen aynı iken $600^{\circ} \mathrm{C}$ 'den sonra birim kütle başına düşen oksitlenme miktarı görülebilir artış gösterdi ve bu artış $800^{\circ} \mathrm{C}$ 'de belirgin olarak gözlendi. Belirtilen sıcaklıklarda kütle kazanımı-zamana bağlı olarak doğrusal değişim gösterdi. Elde edilen sonuçlar 1şı̆̆ında numunelerin oksitlenme oranı denklem 1'den faydalanarak hesaplandı. Burada ( $\triangle W / A)$ birim alan başına kütle kazancı, $k_{p}$ oksitlenme sabiti ve $t$ oksitlenme zamanıdır.

$$
(\Delta W / A)^{2}=k_{p} t
$$

Şekil 2'den faydalanılarak $k_{p}$ değerlerini hesaplanmak için Şekil 3'deki grafik çizildi ve $(\Delta W / A)^{2}$-t grafiğinin eğiminden $k_{p}$ değerleri hesaplandı. Bulunan oksidasyon sabiti değerleri Tablo 1'de verildi. Tablo 1'deki değerlerden de görüldüğü gibi sıcaklık arttıkça oksitlenme miktarına bağlı olarak $k_{p}$ değerlerinin de arttığı görüldü. Sonuçlara göre $400-800^{\circ} \mathrm{C}$ arasındaki oksitlenme sabitleri $0,137.10^{-8}$ $164.10^{-8} \mathrm{mg}^{2} \cdot \mathrm{cm}^{-4} \mathrm{~s}^{-1}$ aralı̆̆ında değiştiği belirlendi. 


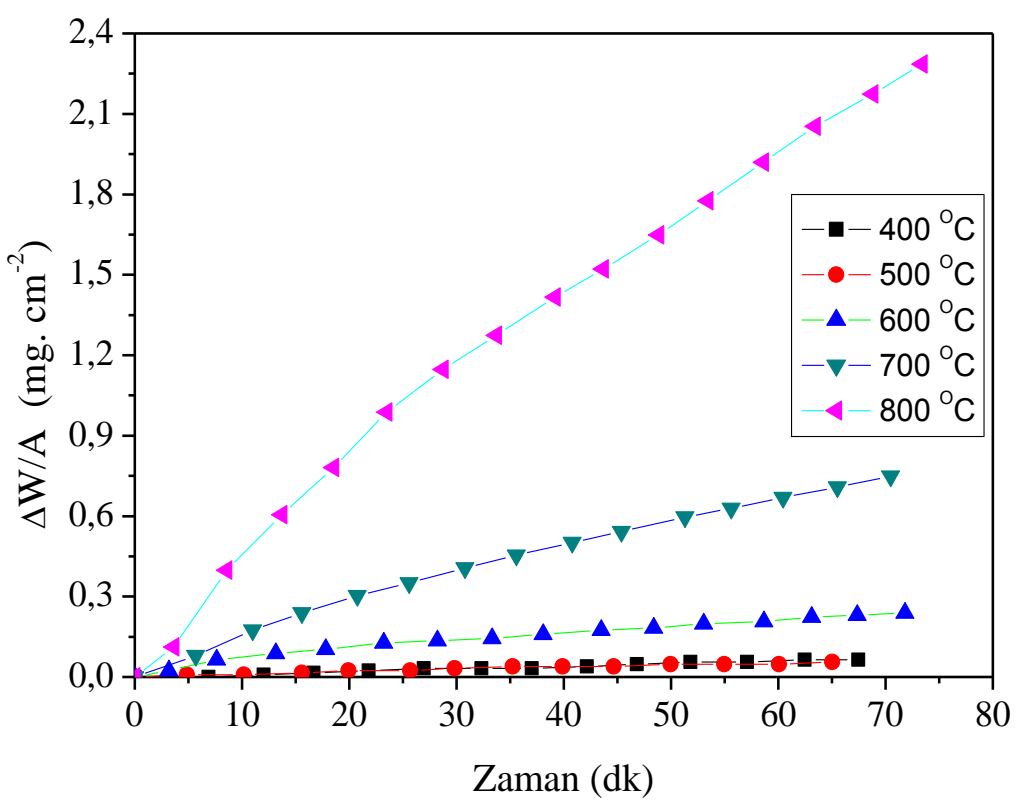

Şekil 2. Hava ortama için 1 saat oksitlenmeye maruz kalan alaşımın farklı sıcaklıklardaki kütle kazanımı

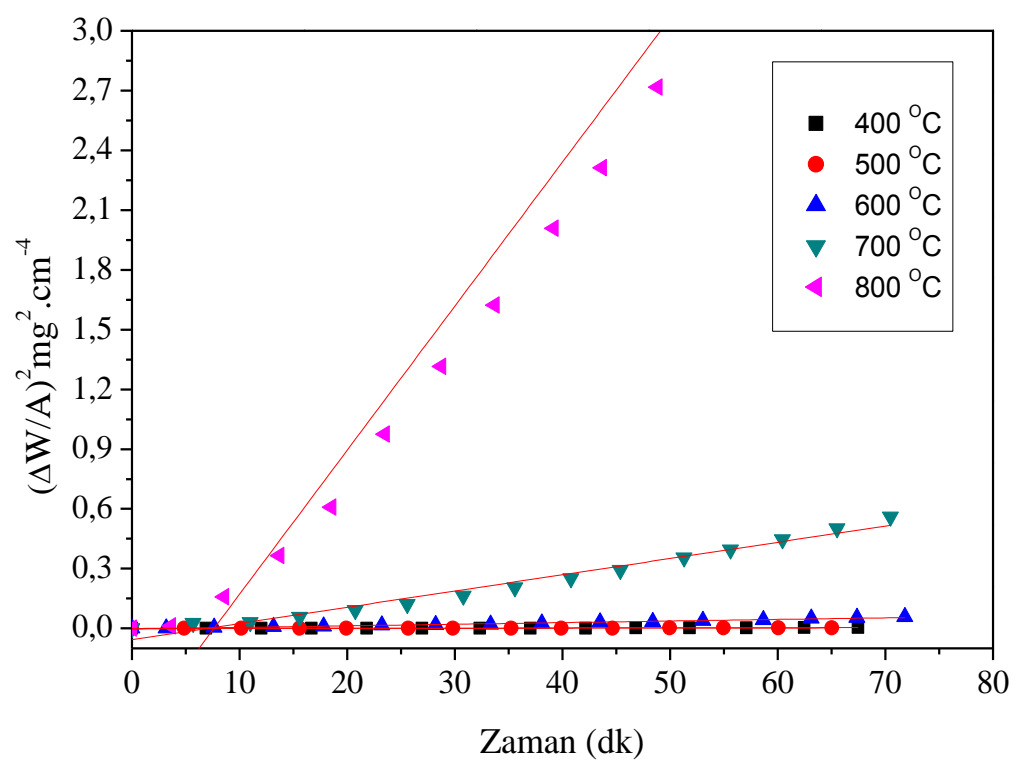

Şekil 3. Hava ortamı için 1 saat oksitlenmeye maruz kalan alaşımın farklı sıcaklıklardaki kütle kazanımının karesi

Tablo 1. $400-800^{\circ} \mathrm{C}$ sıcaklık aralığındaki alaşımın hava ortamındaki oksidasyon sabitleri

\begin{tabular}{|l|l|l|l|l|l|}
\hline Sicaklık $\left({ }^{\circ} \mathbf{C}\right)$ & $4400^{\circ} \mathrm{C}$ & $5500^{\circ} \mathrm{C}$ & $6600^{\circ} \mathrm{C}$ & $7700^{\circ} \mathrm{C}$ & $8800^{\circ} \mathrm{C}$ \\
\hline $\mathbf{k}_{\mathbf{p}}$ hava $\left(\mathbf{m g}^{2} \cdot \mathbf{c m}^{-4} \mathbf{s}^{-1}\right) \mathbf{x 1 0}$ & 00,137 & 11,08 & 11,98 & 018,6 & 0164 \\
\hline
\end{tabular}


Elde edilen oksitlenme sabitlerinden faydalanılarak Şekil 4'deki $\ln k_{p}-1000 / T$ ' grafiği çizildi. Çizilen grafiğgin eğimi ve denklem 2 (Arrhenius denklemi) kullanılarak NiTi alaşımının hava ortamında oksitlenmesi için gerekli olan aktivasyon enerjisi 111,64 kJ/mol olarak bulundu. Burada: $E_{0}$ oksitlenme için aktivasyon enerjisi, $k_{0}$ sabit, $T$ sıcaklık ve $R(8.3145 \mathrm{j} /(\mathrm{mol} . \mathrm{K}))$ genel gaz sabitidir.

$$
k_{p}=k_{0} \exp \left(-E_{0} / R T\right)
$$

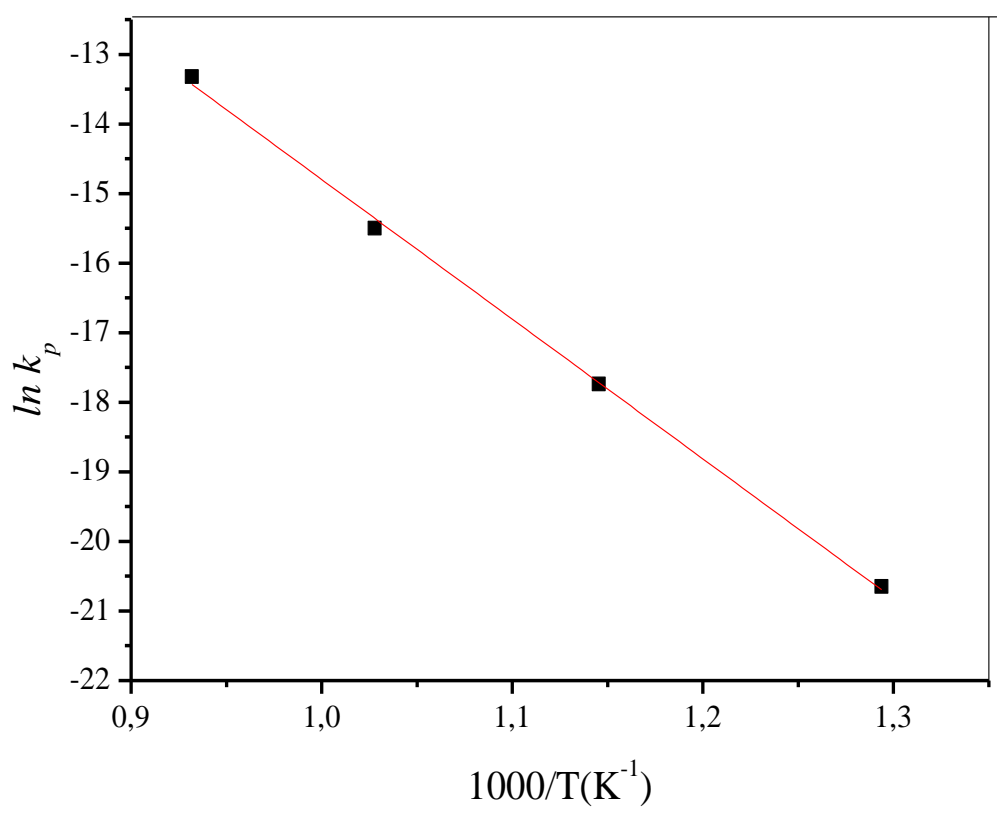

Şekil 4. Hava ortamı için doğrusal oksidasyon sabitinin $(\mathrm{kp}) 500$ ile $800^{\circ} \mathrm{C}$ sıcaklık aralığ 1 için Arrhenius eğrisi

Şekil hatırlamalı NiTi alaşımının dönüşüm sıcaklıklarına (Ms, Mf, As ve Af ) hava ortamının etkisini gözlemlemek için DSC ölçümleri alındı. Şekil 5'de $400-800^{\circ} \mathrm{C}$ aralı̆̆ında belirlenen sıcaklıklarda ve oksitlendirilmemiş NiTi alaşımları için DSC eğrileri görülmektedir. Dönüşüm sıcaklıklarının değişimi ise Tablo 2'de verilmiştir. 


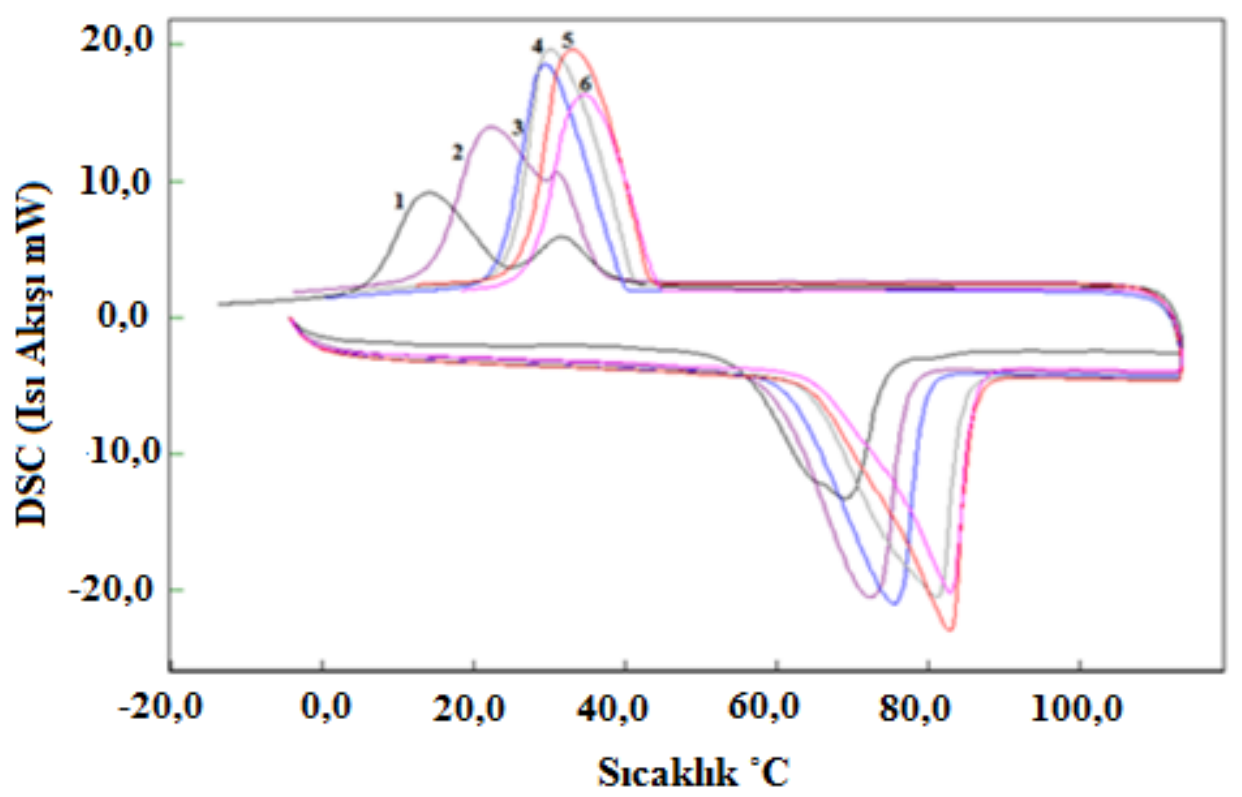

Şekil 5. NiTi 'nin farklı sıcaklıklarda ki DSC eğrileri (1-oksitlendirilmemiş NiTi, 2-400 ${ }^{\circ} \mathrm{C}, 3-500^{\circ} \mathrm{C}$, 4$\left.600^{\circ} \mathrm{C}, 5-700^{\circ} \mathrm{C}, 6-800^{\circ} \mathrm{C}\right)$

Tablo 2. $400-800^{\circ} \mathrm{C}$ arasındaki ve oksitlendirilmemiş NiTi alaşımının dönüşüm sıcaklıkları değerleri

\begin{tabular}{|c|c|c|c|c|c|c|c|c|}
\hline $\begin{array}{l}\text { Dönüşümm } \\
\text { Sicaklıkları }\end{array}$ & $\mathbf{A}_{s} /{ }^{\circ} \mathbf{C}$ & $\mathbf{A}_{\mathrm{f}} /{ }^{\circ} \mathbf{C}$ & $\mathbf{A}_{\mathbf{p}} /{ }^{\circ} \mathbf{C}$ & $\mathbf{M}_{s} s^{\circ} \mathbf{C}$ & $\mathbf{M}_{\mathbf{f}} /^{\circ} \mathbf{C}$ & $\mathbf{R}_{\mathbf{p}} /{ }^{\circ} \mathbf{C}$ & $\mathbf{R}_{\mathrm{f}} /{ }^{\circ} \mathbf{C}$ & $\mathbf{M}_{\mathbf{p}} /{ }^{\circ} \mathbf{C}$ \\
\hline $\begin{array}{l}\text { Oksitlendirilmemiş } \\
\text { Numune (1) }\end{array}$ & 55,0 & 74,4 & 69,0 & 38,8 & 6,4 & 31,8 & 26,8 & 24,4 \\
\hline $400^{\circ} \mathrm{C} \mathrm{(2)}$ & $\overline{59,8}$ & 777,0 & 72,5 & 36,8 & 14,6 & 31,3 & --- & 22,2 \\
\hline $500^{\circ} \mathrm{C}(3)$ & 61,7 & 79,5 & 75,4 & 39,9 & 23,4 & --- & --- & 29,4 \\
\hline $600^{\circ} \mathrm{C}$ (4) & 63,9 & 84,5 & 81,3 & 41,5 & 24,8 & --- & -- & 30,2 \\
\hline $700^{\circ} \mathrm{C}(5)$ & 63,6 & 85,8 & 82,9 & 43,1 & 27,1 & --- & --- & 33,1 \\
\hline $800^{\circ} \mathrm{C}(6)$ & 65,2 & 86,3 & 83,1 & 44,4 & 28,1 & --- & --- & 34,4 \\
\hline
\end{tabular}

Oksitlendirilmemiş numune ile $400^{\circ} \mathrm{C}^{\prime}$ de oksitlendirilen NiTi alaşımında, faz geçişi iki adımda meydana gelmiştir. İlk adımda B2 (Kübik)' den R (Rombohedral)' ye, ikinci adımda ise R' den B19 (Monoklinik)' a faz geçişi olmuştur. Oksitlenmiş NiTi alaşımı için, 500 ile $800^{\circ} \mathrm{C}$ arasındaki sıcaklıklarda ise $\mathrm{R}$ fazı kaybolmuştur. NiTi alaşımının faz dönüşümleri uygulanan sıcaklıklara bağlı olarak; $400^{\circ} \mathrm{C}$ altındaki sicaklıklarda $\mathrm{B} 2 \leftrightarrow \mathrm{R}, 400-600^{\circ} \mathrm{C}$ arasındaki sicakliklarda $\mathrm{B} 2 \leftrightarrow \mathrm{R} \leftrightarrow \mathrm{B} 19$ ve $600^{\circ} \mathrm{C}$ üzerindeki sıcaklıklarda $\mathrm{B} 2 \leftrightarrow \mathrm{B} 19$ şeklinde meydana geldiği bilinmektedir [11]. Hava ortamındaki alaşımın; austenit ve martensitik dönüşüm sıcaklıklarının, oksitlenme sıcaklığının arttırılması ile arttığı gözlenmiştir.

Oksitlenmiş numunelerin yüzey karakterizasyonu Taramalı Elektron Mikroskopu (SEM) kullanılarak incelendi. Şekil hatırlamalı alaşımın kimyasal bileşimleri hakkında bilgi sahibi olabilmek için ise numunenin yüzeyinden alınan enerji ayırım X-1̧̧ını spektrometresi (EDX) analizi yapıldı. Şekil 6'da 400, 500, 600 ve $700{ }^{\circ} \mathrm{C}$ 'deki EDX spektrum sonuçları görülmektedir. Numunelerde bulunan 
element miktarları ise $400^{\circ} \mathrm{C}$ 'de; ağırlıkça $\% 12,98 \mathrm{O}, \% 38,42 \mathrm{Ti}, \% 46,19 \mathrm{Ni}, \% 2,14 \mathrm{C}$ ve $\% 0,27 \mathrm{Si}$, $500^{\circ} \mathrm{C}$ 'de; ağırlıkça $\% 23,71 \mathrm{O}, 36,42 \mathrm{Ti}, \% 38,06 \mathrm{Ni}, \% 1,37 \mathrm{C}$ ve \% $0,44 \mathrm{Al}, 600^{\circ} \mathrm{C}$ 'de; ağırlıkça \% $45,5 \mathrm{O}, 46,6 \mathrm{Ti}, \% 5,03 \mathrm{Ni}, \% 2,39 \mathrm{Cu}$ ve $\% 0,48 \mathrm{Si}, 700^{\circ} \mathrm{C}$ 'de; ağırlıça \% 39,95 O, \% 57,84 Ti ve \% 2,21 Ni elementleri bulunmuştur. Oksitlenme sıcaklıklarının arttırılmasıyla numunedeki O miktarının arttığı, belirli bir sıcaklıktan sonra numunedeki oksijen miktarının azaldığı buna karşın Ti miktarının arttığı görülmüştür. Oksitlenmeye bırakılan NiTi alaşımının içerisine nüfuz eden O miktarı sıcaklığın artmasına karşı değişmektedir. Bu değişim SEM fotoğraflarında görüldüğü gibi artan sıcaklık ile tane yapısının değişip elementlerin çekirdek büyüklüklerinin artmasıyla meydana gelir. Artan çekirdek hacminden dolayı numune içerisindeki Nİ ve Ti elementleri arasındaki boşluklar azalmakta ve nüfuz eden $\mathrm{O}$ miktarı azalmaktadır. Numunede bulunan $\mathrm{C}$, $\mathrm{Si}$ ve $\mathrm{Cu}$ elementleri numunenin yüzey pürüzlülügünün sağlanmasında yapılan zımpara işlemi ve cihazda meydana gelen kirlenmelerden oluştuğu düşünülmektedir.

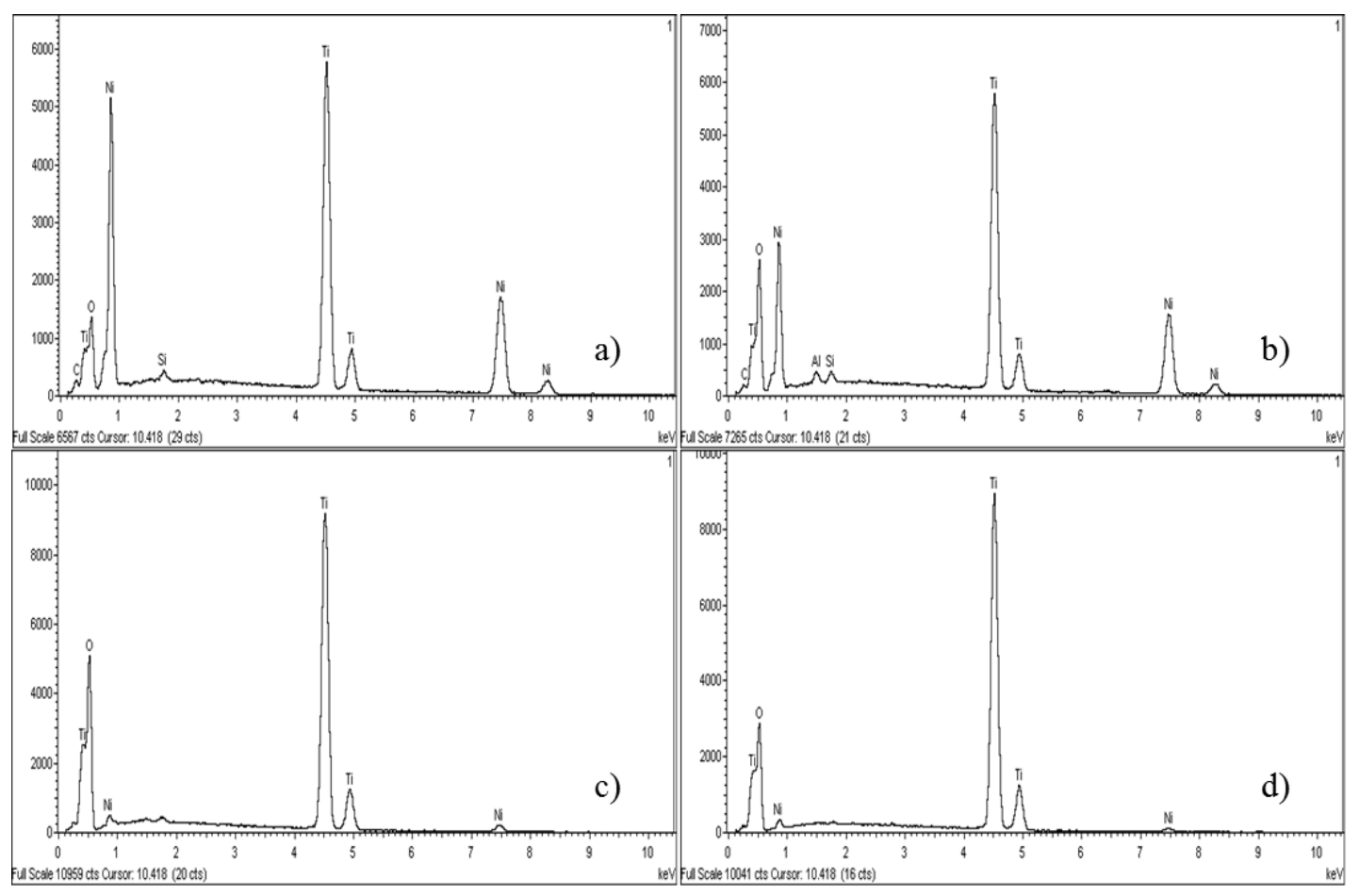

Şekil 6. Hava ortamı için NiTi alaşımının izotermal oksidasyon davranışları sonrası elde edilen EDX spektrumlar $\left(\mathbf{a}-400^{\circ} \mathrm{C}, \mathbf{b}-500^{\circ} \mathrm{C}, \mathbf{c}-600^{\circ} \mathrm{C}, \mathbf{d}-700^{\circ} \mathrm{C}\right)$

Şekil 7'de hava ortamında $400,500,600,700$ ve $800^{\circ} C^{\prime}$ 'de oksitlendirilen numunelerin SEM görüntüleri gösterilmektedir. Düşük sıcaklıklardaki numunenin yüksek sıcaklıklardaki numuneye göre daha düşük oksitlenme gösterdiği görüldü. Ayrıca sıcaklık artışı ile tane yapısının değiştiği ve yeni martensit plakalarının oluştuğu gözlendi. 

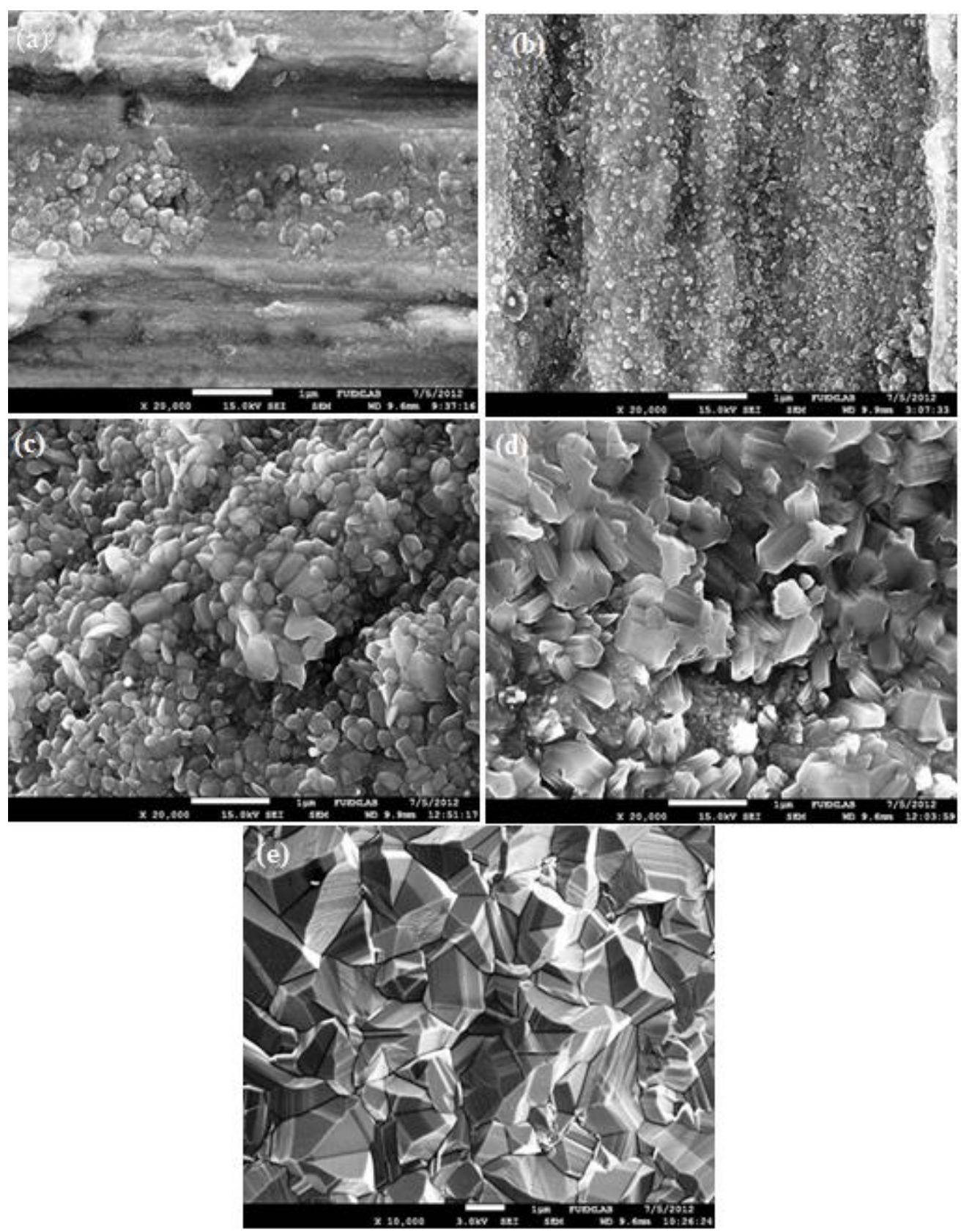

Şekil 7. Hava ortamı için NiTi alaşımının izotermal oksidasyon davranışları sonrası elde edilen SEM görüntüleri $\left(\mathbf{a}-400^{\circ} \mathrm{C}, \mathbf{b}-500^{\circ} \mathrm{C}, \mathbf{c}-600^{\circ} \mathrm{C}, \mathbf{d}-700^{\circ} \mathrm{C}\right.$ e- $\left.-800^{\circ} \mathrm{C}\right)$ 


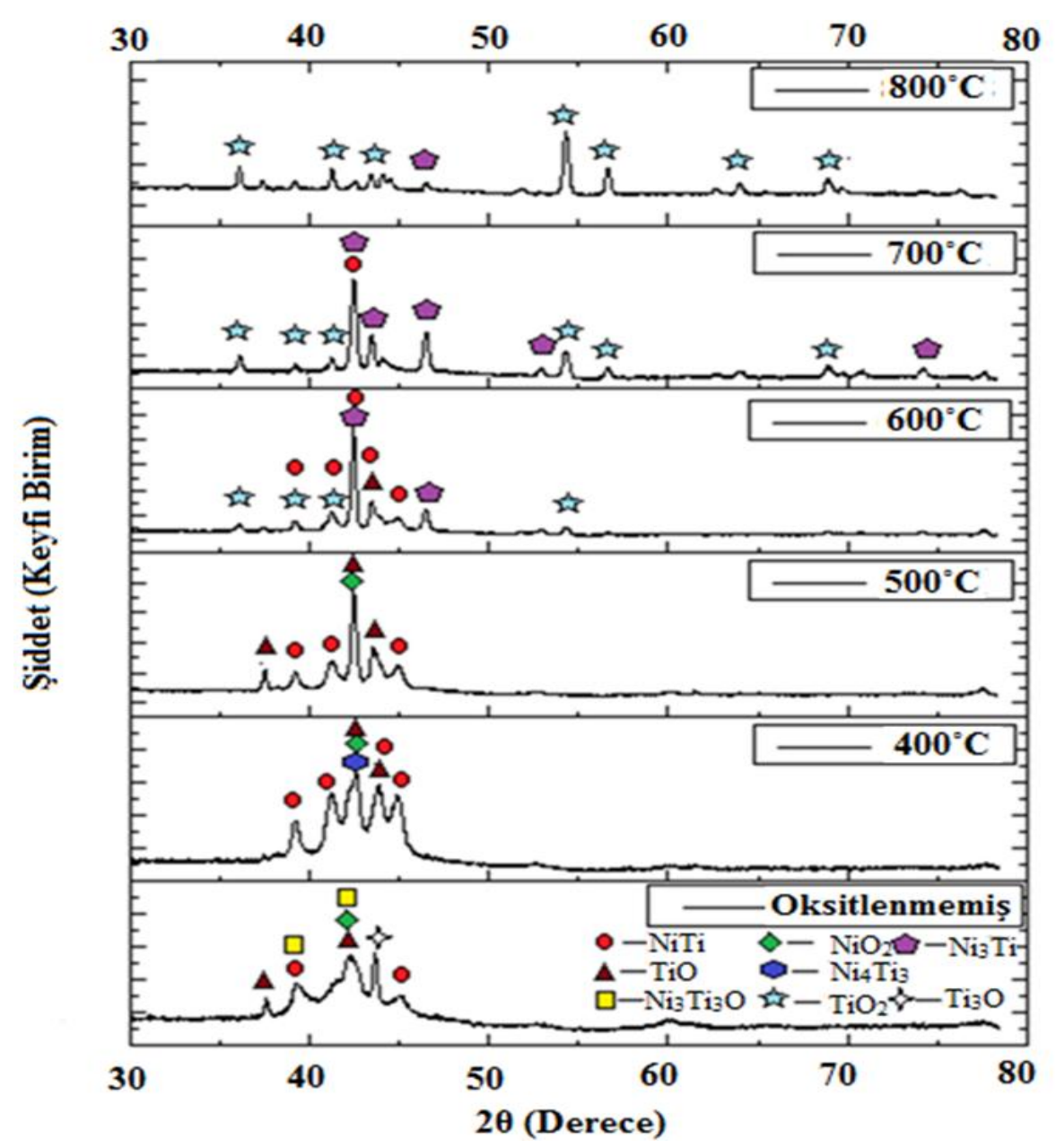

Şekil 8. Hava Ortamı X-Işını Analiz Fotoğrafı

Oksitlendirilmemiş numuneye ait X-1̧̧ını analizinde $\mathrm{NiTi}$ (B2), $\mathrm{NiTi}$ (B19), $\mathrm{Ni}_{3} \mathrm{Ti}_{3} \mathrm{O}, \mathrm{TiO}, \mathrm{NiO}_{2}$ ve $\mathrm{Ti}_{3} \mathrm{O}$ fazlarına ait pikler Şekil 8 'de görülmektedir. $400^{\circ} \mathrm{C}$ 'de hava ortamında oksitlendirilmiş numunede $\mathrm{TiO}$ piklerinin yanı sıra $\mathrm{Ni}_{4} \mathrm{Ti}_{3}$ ve $\mathrm{NiO}_{2}$ piklerini de içerdiği görüldü. Oksidasyon sıcaklığının arttırıldı $\breve{g}_{1} 500^{\circ} \mathrm{C}$ ' deki numunenin NiTi (B2) fazının piki ile $\mathrm{NiO}$ ve TiO pikleri belirginleşti ve diğer piklerin kaybolduğu gözlendi. $600^{\circ} \mathrm{C}$ 'de oksitlenmeye maruz bırakılan numunede ise NiTi (B2) ile NiTi (B19) fazlarının piklerinin yanı sıra, $\mathrm{TiO}_{2}$ ve $\mathrm{Ni}_{3} \mathrm{Ti}$ fazının pikleri meydana geldi. $700^{\circ} \mathrm{C}$ 'de oksitlenen numunede $\mathrm{TiO}_{2}$ ve $\mathrm{Ni}_{3} \mathrm{Ti}$ pikleri artış gösterdi. $800^{\circ} \mathrm{C}$ 'de oksitlenen numunelerde ise NiTi (B2) fazının pikleri kayboldu ve $\mathrm{TiO}_{2}$ piki ile $\mathrm{Ni}_{3}$ Ti fazının pikleri daha da belirginleştiği görüldü.

Nikelce zengin NiTi şekil hatırlamalı alaşımlarda düşük sıcaklıklar için görülen ötektik dönüşümlerle, Ni çözünürlüğü azalıp yapıda oluşan yarı kararlı $\mathrm{Ni}_{4} \mathrm{Ti}_{3}$ fazı çökelme imkânı bulur. NiTi alaşımlarının 300 ile $600^{\circ} \mathrm{C}$ arasında tavlandığında $\mathrm{Ni}_{4} \mathrm{Ti}_{3}$ fazının büyüdüğü ve kararlı $\mathrm{Ni}_{3} \mathrm{Ti}$ fazına dönüştüğü bilinir. $\mathrm{Ni}_{4} \mathrm{Ti}_{3}$ fazını içeren düşük sıcaklıklarda ki NiTi alaşımlarında, B2↔R↔B19 dönüşümü gözlenirken, $\mathrm{Ni}_{3} \mathrm{Ti}$ fazını içeren yüksek sıcaklıklarda ise $\mathrm{B} 2 \leftrightarrow \mathrm{B} 19$ dönüşümü görülür [12].

\section{Sonuçlar}

Hava ortamında oksitlendirilmemiş numune ile 400,500,600, 700 ve $800^{\circ} \mathrm{C}$ 'de oksitlendirilmiş numunelerin dönüşüm sıcaklıkları incelendiğinde, oksitlendirilmemiş numunenin martensit ve austenit dönüşüm sıcaklıkları $6,4{ }^{\circ} \mathrm{C}$ ile $74,4{ }^{\circ} \mathrm{C}$ arasında meydana gelirken, $400{ }^{\circ} \mathrm{C}$ 'de $14,6{ }^{\circ} \mathrm{C}$ ile $77,0{ }^{\circ} \mathrm{C}, 500$ ${ }^{\circ} \mathrm{C}$ 'de $23,4{ }^{\circ} \mathrm{C}$ ile $79,5{ }^{\circ} \mathrm{C}, 600{ }^{\circ} \mathrm{C}$ 'de $24,8{ }^{\circ} \mathrm{C}$ ile $84,5{ }^{\circ} \mathrm{C}, 700{ }^{\circ} \mathrm{C}$ 'de $27,1{ }^{\circ} \mathrm{C}$ ile $85,8{ }^{\circ} \mathrm{C}$ ve $800{ }^{\circ} \mathrm{C}$ 'de 
$28,1{ }^{\circ} \mathrm{C}$ ile $86,3{ }^{\circ} \mathrm{C}$ aralıklarında değişmektedir. S1caklık arttıkça dönüşüm sıcaklıklarının arttığı, $\mathrm{M}_{\mathrm{s}}$ ve $\mathrm{A}_{\mathrm{f}}$ arasındaki dönüşüm sıcaklık farkının azalıp daha kararlı hale geldiği görüldü. Oksitlendirilmemiş numune ile hava ortamında $400^{\circ} \mathrm{C}$ 'de oksitlendirilmiş numunede $\mathrm{R}$ fazı görülürken, oksitlenme sıcaklıklarının arttırıldığı 500, 600, 700 ve $800^{\circ} \mathrm{C}$ 'deki sıcaklıklarda R fazının kaybolduğu görüldü.

Şekil hatırlamalı NiTi alaşımının artan sıcaklık ile hava atmosferine maruz kalması sonucu alaşım yüzeyinde oksit tabakalarının oluştuğu gözlendi. Numunenin $400{ }^{\circ} \mathrm{C}$ 'de oksitlenmesinden sonra oksit tabakası Şekil-7-a'da gözlendi. Bu oksit tabakası EDX spektrumu ve X-1şını ile TiO olduğu belirlendi. Tane boyutunun oldukça küçük olması nedeniyle tanelerin görülmediği anlaşıldı. Artan oksidasyon sıcaklığı ile ortalama tane boyutu Şekil 7-b ve 7-c'de görüldüğü gibi artmaya başladı. Numune yüzeyinde şekillenen yeni oksit tabakası EDX spektrumu ve X-1şını analizi ile $\mathrm{TiO}$ ve $\mathrm{TiO}_{2}$ olduğu belirlendi. Şekil 7-d'de görülen SEM görüntüsünde ise numunenin tane yapısı değişmeye başladı. Çubuk şeklinde oluşan yapı martensit plakaları içerdiği görüldü. Oluşan bu martensit plakaların kendince oluşan (self-accommodating) martensit plakalar olduğu belirlendi [13]. Yeni oluşan bu martensit plakalar Şekil 7-d'de ok işareti ile belirtildi. DSC sonuçları ile karşılaştırıldığında yeni oluşan bu martensit plakalar R fazının kaybolmasına neden olmuştur. NiTi alaşımlarında $630{ }^{\circ} \mathrm{C}$ civarında meydana gelen ötektik reaksiyonlardan dolayı çökelmeler oluşur, yeni martensit plakalar belirir ve böylece R fazının kaybolmasına sebep olur [14]. $800{ }^{\circ} \mathrm{C}$ 'de oksitlenmiş numunenin yüzey morfolojisi ise Şekil 7-e'de görülmektedir. Çubuk şeklindeki tanelerin daha da büyüdüğü, dolayısıyla martensit plakaların daha net bir şekilde oluştuğu görüldü.

Çalışmadaki X-1şını analizlerinde bulunan pikler Şekil 8'de gösterilmiştir. Oksitlendirilmemiş numunede TiO, $\mathrm{NiTi}, \mathrm{Ni}_{3} \mathrm{Ti}_{3} \mathrm{O} \mathrm{NiO}{ }_{2}$ ve $\mathrm{Ti}_{3} \mathrm{O}$ pikleri bulundu. $400{ }^{\circ} \mathrm{C}$ 'de ise $\mathrm{Ni}_{3} \mathrm{Ti}_{3} \mathrm{O}$ pikinin yerine $\mathrm{Ni}_{4} \mathrm{Ti}_{3}$ piki oluştuğu görüldü. $\mathrm{Ni}_{3} \mathrm{Ti}_{3} \mathrm{O}$ ve $\mathrm{Ni}_{4} \mathrm{Ti}_{3}$ pikleri DSC analizinde belirlenen $\mathrm{R}$ fazını desteklediği belirlendi. Ayrıca TiO pikinin oksitlenme ve sıcaklık artışına bağlı olarak arttı̆̆ görüldü. $400{ }^{\circ} \mathrm{C}$ 'de R fazını oluşturan $\mathrm{Ni}_{4} \mathrm{Ti}_{3}$, piki ötektik reaksiyon sonucu $\mathrm{Ni}_{3} \mathrm{Ti}$ pikine dönüştüğü, böylece $\mathrm{R}$ fazının kaybolduğu belirlendi. Tablo 2 'de verilen dönüşüm sıcaklıkları incelendiğinde $400^{\circ} \mathrm{C}$ 'den sonra $\mathrm{R}$ fazının kaybolmasiyla bu durum desteklendi.

Oksitlenme sicaklıklarının arttırılmasıyla $\left(600,700\right.$ ve $\left.800{ }^{\circ} \mathrm{C}\right)$ TiO pikinin yanı sira $\mathrm{TiO}_{2}$ piklerinin de oluştuğu gözlendi.

\section{Kaynaklar}

1. Kök M., Yıldız K. 2014. Oxidation Parameters Determination of $\mathrm{Cu}-\mathrm{Al}-\mathrm{Ni}-\mathrm{Fe}$ Shape-Memory Alloy at High Temperatures Appl. Phys. A., DOI 10.1007/s00339-014-8394-3.

2. Kök M., Pirge G., Yıldırım A. 2013. Isothermal Oxidation Study on NiMnGa Ferromagnetic Shape Memory Alloy at 600-1000 ${ }^{\circ}$ C., Appl. Surface Sci., 268: 136-140.

3. Bazochaharbaks E. 2011Surface Nitrating and Oxidation of Nitinol, Master Thesis, San Jose State University.

4. Degeratu S., Rotaru P., Manolea G., Monolea H. Rotaru A. 2009.Thermal Characteristics of NiTi SMA (Shape Memory Alloys) Actuators. J. Therm Anal Calorim., 97: 695-700.

5. Morgan N.B. 2004. Medikal Shape Memory Alloy Applications-the Market and its Products, Mater Sci. Eng., A378: 16-23.

6. Thomson S.A. 2000. An Overview of Nickel-Titanyum Alloys Used in Dentistry, Int. Endod J., 33: 297-310.

7. Duering T., Pelton A., Stöckel D. 1999. An Overview of Nitinol Medical Applications, Mater Sci Eng., A273-A275: 149-160.

8. Lin K.L., Wu S.K. 2009. Oxidation Behavior of Ti50Ni40Cu10 Shape Memory Alloys in 700$1000^{\circ} \mathrm{C}$ Air, Oxid. Met., 71: 187-200. 
9. Chu CL., Wu S.K., Yen, Y.C. 1996. Oxidation Behavior of Equiatomic TiNi Alloy in High Temperature Air Environment, Mat. Sci. Eng., 216: 193-200.

10. Firstov G.S., Vitchev R.G., Kumar H., Blanpain B., Van Humbeeck J. 2002. Surface Oxidation of NiTi Shape Memory Alloys, Biomaterials, 23: 4863-4871.

11. Dağdelen F., Ercan E. 2014. The Surface oxidation behavior of Ni-45.16\%Ti Shape Memory Alloys at Different Temperatures J.l Thermal Anaysis Calorim, 115: 561-565.

12. Cesari E., Santamarta R., Pons J., Segui C. 1999. Ageing Effects in Ni-Ti Shape Memory Alloys, Dept. de Fisica, Universitat de Illes Balears, 443-452 Mallorca.

13. Aydoğdu Y., Aydoğdu A., Adıgüzel O. 2002. Self-accommodating martensit plate variants in shape memory CuAlNi alloys J. Mater. Process, 24: 498-500.

14. Gupta K.P. 2003. The Ni-Rh-Ti (nickel-rhodium-titanium) system. J. Phase Equilib., 24: 4768.

Geliş Tarihi: 26/03/2015

Kabul Tarihi: 13/05/2015 